\title{
Investigation of the Properties of Fibrous Cotton Seeds, for Sorting on a Mesh Surface
}

\author{
Avazbek Obidov, Khamid Akhmedhodjaev, Olimjon Sarimsakov, Qurbonali Holikov
}

Namangan Institute of Engineering and Technology, Namangan, Uzbekistan

Email: olimjon5008@mail.ru

How to cite this paper: Obidov, A., Akhmedhodjaev, K., Sarimsakov, O. and Holikov, Q. (2018) Investigation of the Properties of Fibrous Cotton Seeds, for Sorting on a Mesh Surface. Engineering, 10, 572-578. https://doi.org/10.4236/eng.2018.109041

Received: June 25, 2018

Accepted: August 31, 2018

Published: September 3, 2018

Copyright $\odot 2018$ by authors and Scientific Research Publishing Inc. This work is licensed under the Creative Commons Attribution International License (CC BY 4.0).

http://creativecommons.org/licenses/by/4.0/

\begin{abstract}
In the article the research of cotton seeds for the purpose of increasing the fiber in the enterprise is investigated, separated from the mass of the derivatives of ginning of fibrous seeds by means of effective cleaning and sorting on the mesh surface.

\section{Keywords}

Cotton Seeds, Cotton Fiber, Litter, Technical Seeds, Sowing Seeds, Lint, Gin, Sorting, Moisture, Selection, Variety, Fibrous Seeds
\end{abstract}

\section{Features of Cotton Seeds Processing after Ginning}

The production of cotton products and the cotton industry occupy an important place in the economy of Uzbekistan, as a result of which a number of decrees and higher-level decisions on the cardinal transformation of this sphere of the economy have been adopted lately [1] [2], and the output of cotton for the last 5 years has been declining, and its consumption within the country is gradually increasing [3]. The country is striving to rebuild its economy with the production of deep processing of cotton, bringing raw cotton to finished products. Therefore, scientific research aimed at improving the quantitative and qualitative indicators of cotton products for the country is of great importance.

In cotton cleaning enterprises, after the ginning process, cottons get polluted with sand, soil, weeds, metal objects and stalks. Besides that, in the next treatment, beaten apart and not fully grown seed mass might be met likewise this increases in spiral conveyors when treating cotton fiber and lint. In this mass there might be missed parts of cotton and light aerodynamic objects in collecting conveyor. Cottons picked in combine machines get too polluted. It is considered to be the main cause of pollution of cotton with organic impurities, leaves, cotton stems. In the separation of the fiber from the seeds of the bulk of the debris, 
it goes into the composition of seeds and the separation of short fibers (of lint) from seed it goes into the composition of the lint. The degree of purity of the lint is the main factor determining the quality of the lint, especially if the lint is intended for use in paper production. Cotton seeds are divided into technical, treating cotton seed oil enterprises and seed.

The technical seeds are divided into four industrial sorts taking from cotton product [4].

In fully grown cotton the portion of cotton seeds is around $55.0 \%$ to $63.9 \%$.

Cleanliness, moisture and fibrous level of cotton seeds delivered to cotton seed oil enterprises should correspond to norms of UzRST 633-2010 and UzRST 645-2010 (Table 1 and Table 2).

In treating of cotton seeds, fully separated seeds from cotton and rest fibrous level are analyzed and defined. In order to use cotton seeds in both purposes; making cotton seed oil and sowing material are required minimal fibrous level of cotton. The less the fibrous seed, the higher level the taking oil and the better the vegetation period of seeds.

In addition, the fibrous level of cotton seeds is important in the rational use of raw materials. The greater the degree of the residual fibrous of the treated cotton seeds, the greater the generation of lint and delint.

The content of long fibers in the seed composition after the fiber separation stage depends on the distance between the grate of Gin, the type of the picking of cotton and industrial cotton varieties. Fully purified cotton seeds make up an equal part of the mass of the remaining fibers after Ginning or Lintering process.

The classification and technical demands of planting are indicated in DAST 610-2008 [5]. According to the cleanliness sort of seeds they are divided into following groups (Table 3 ).

Table 1. Quality indicators of cotton seeds according to standards.

\begin{tabular}{ccccc}
\hline \multirow{2}{*}{$\begin{array}{c}\text { The sort } \\
\text { of seeds }\end{array}$} & $\begin{array}{c}\text { The portion of } \\
\text { non-acceptable seeds \% }\end{array}$ & $\begin{array}{c}\text { Portion of } \\
\text { moisture to weight }\end{array}$ & $\begin{array}{c}\text { Average } \\
\text { fiber cotton sort }\end{array}$ & $\begin{array}{c}\text { Thin fiber } \\
\text { of cotton sort }\end{array}$ \\
\hline I & 1.5 & 10.0 & $5.0-10.5$ & $2.0-6.5$ \\
II & 3.0 & 11.0 & $6.0-10.5$ & $3.0-7.5$ \\
III & 11.0 & 12.0 & $7.0-10.5$ & $4.0-8.5$ \\
IV & 33.0 & 13.0 & $8.0-10.5$ & $4.5-9.0$ \\
\hline
\end{tabular}

Table 2. Color of cotton seeds according to standards.

\begin{tabular}{cc}
\hline The sort of cotton seeds & The colour of cotton seed in nucleus cut \\
\hline I & $\begin{array}{c}\text { Green like and other silicon shadow proof } \\
\text { depending on selection sort of cotton }\end{array}$ \\
II & Silicon shadow proof depending on selection of cotton \\
III & Almost grey silicon yellowish shadow proof \\
IV & From yellow to bright brown \\
\hline
\end{tabular}


Table 3. The purity of seeds, depending on the variety.

\begin{tabular}{cc}
\hline Cleanliness sort of seeds & Sort cleanliness \% \\
\hline The Elite sort & 100 \\
The first sort & 99 \\
The second sort & 98 \\
The third sort & 96 \\
\hline
\end{tabular}

\section{The Purpose of the Study of the Processing of Ginning Seeds}

As we know, cleaning and sorting machines were built under the trend of separating fiber mixture their physical-mechanical properties. Dividable sign of mixture is aerodynamic properties, dimensions (width, thickness and length), the peculiarities of surfaces. The productivity of separating into fraction depends on high difference between fractions in seed mixtures.

Practically, the technical process of cleaning and regenerating machine accomplishes to carry out the process until it demands material from regenerating machine. By this way the cost of working expense, cleaning or regeneration rises. Here cleaning and regenerating quality is up to the number of conducting through the machine, it gets clear the right choice of mixture, its dividable sign, depending on working routine of mechanical facilities and worker organs (parts) in order to separate it.

There are three methods are used to separate them [6] [7]:

- aeromechanical;

- by mechanical facilities;

- separating by the difference of material surface.

Selecting mixtures that has seeds into fractions is carried out with air volume by spray or sucker ventilations. Here the air volume should be smooth (normal line) and stable, seed mixture should be passed in a slender sickness smoothly, continuously. In practice, vertical and inconstant air volume constructions are used, so here selecting mixtures are accomplished accordingly its aerodynamic properties. To these flows the coming of fractions mixture is pulled with air volume and using this stream vertically up shoot farther than fractions with little aerodynamic properties. The same action is carried out with sucker type of facilities.

The aim and problems of research is working on recommendations making technologies based on recycling fibrous fractions after ginning process and reducing incorrect operations during the process taking extra fiber, seed, quality of lint.

The physical-mechanical properties of cotton seeds reflect on aerodynamic descriptions and delivery mechanisms that treat their fiber layer.

The main point of cotton seeds' physical-mechanical properties plays main role in recycling cotton seeds and projecting their delivery (transfer) machines as well as making and treating. Scientific researches were carried out mainly on 
analyzing mass centre of cotton seed relying on its form and dimension, for example, bottom part of seed "khalaza" (down part of cotton seed) or micropil (its top). In order to make calculations it would better accept (cut cone and two half spheres) the seeds appeared from the combining three forms.

In some scientific research works, [6] the seeds that come from the gin are based on the existence of two types of residual fertility:

1) Free fibers;

2) Fibers have not removed yet from seeds.

The main reasons for the formation of free fibers are the great variation in the speed of rotation of the raw material and the saw cylinder. When fibrous saws are cylindrical with their teeth, long fibers are subjected to frictional strength in the raw material mass. The raw material has a high density, so some of the fibers removed by the teeth are separated from the teeth and rolled to the raw material valve. Some of these freely fibers are reused by the teeth, while the other part is left in the seeds and goes out with the gin [7] (Table 4).

\section{Theoretical Research to Determine the Properties of Gin Cotton Seeds and Using the Results to Select the Optimal Values}

Using mechanical laws we analyze mass centre of seeds. Here $D_{1} / D$ is equal to average 1.4. In that case, the height of cone is $1.3 R$ (Figure 1 ).

The coordinates of mass centre of cut cone make $Z_{\kappa}=4 H / 9$, half sphere mass center coordinates are $Z_{n c 1}$ and $Z_{n c 2} \quad Z_{n c 1}=32 / 8, Z_{n c 2}=H+32 / 8$, mass centre coordinates of fiber are $Z_{b}=l / 2+H+2$. Here, $R=2 r$.

$$
Z_{c}=\frac{Z n c_{1} \cdot V n c_{1}+Z_{k} V_{k}+Z n c_{2} V n c_{2}}{V n c_{1}+V_{k}+V n c_{2}}
$$

If $V_{c}=V n c_{1}+V_{k}+V n c_{2}$ the cut cone and half sphere volume are determined by $V_{k}=\pi H / 3\left(R^{2}+r^{2}-r R\right) ; V n c_{2}=2 \pi R^{3} / 3 ; V n c_{1}=2 \pi r^{3} / 3$.

Table 4. Characteristics of the common sorts of cotton.

\begin{tabular}{|c|c|c|c|c|c|}
\hline \multirow[b]{2}{*}{ No } & \multirow{2}{*}{$\begin{array}{l}\text { Selections } \\
\text { sorts }\end{array}$} & \multicolumn{4}{|c|}{ Ginned seeds } \\
\hline & & $\begin{array}{c}\text { Length }\left(D_{1}\right) \\
\mathrm{mm}\end{array}$ & $\underset{\mathrm{mm}}{\text { Diameter }\left(\mathrm{D}_{2}\right)}$ & $\begin{array}{c}\text { The mass of } \\
100 / \mathrm{g}\end{array}$ & Fluffiness \% \\
\hline 1 & S-6524 & $8.0-12.25$ & $5.5-8.75$ & 138.2 & 14.2 \\
\hline 2 & S-6530 & $8.2-12.22$ & $5.4-8.84$ & 136.9 & 14.0 \\
\hline 3 & Namangan & $7.25-12.30$ & $5.6-9.0$ & 125.8 & 14.9 \\
\hline 4 & Kirgizia & $7.8-11.4$ & $5.4-8.6$ & 101.6 & 10.2 \\
\hline 5 & An-Bayavut & $7.9-12.31$ & $5.5-8.35$ & 120.9 & 14.5 \\
\hline 6 & S-9070 & $8.1-12.2$ & $5.8-9.8$ & 128.3 & 13.8 \\
\hline 7 & Bukhara-6 & $8.0-12.1$ & $6.1-8.4$ & 126.8 & 14.2 \\
\hline 8 & 9871-И & $8.1-10.2$ & $5.1-6.8$ & 117.3 & - \\
\hline 9 & Ash-25 & $8.1-9.8$ & $4.5-5.3$ & 108.1 & - \\
\hline 10 & 9853-И & $8.2-9.6$ & $5.2-5.8$ & 125.25 & - \\
\hline
\end{tabular}



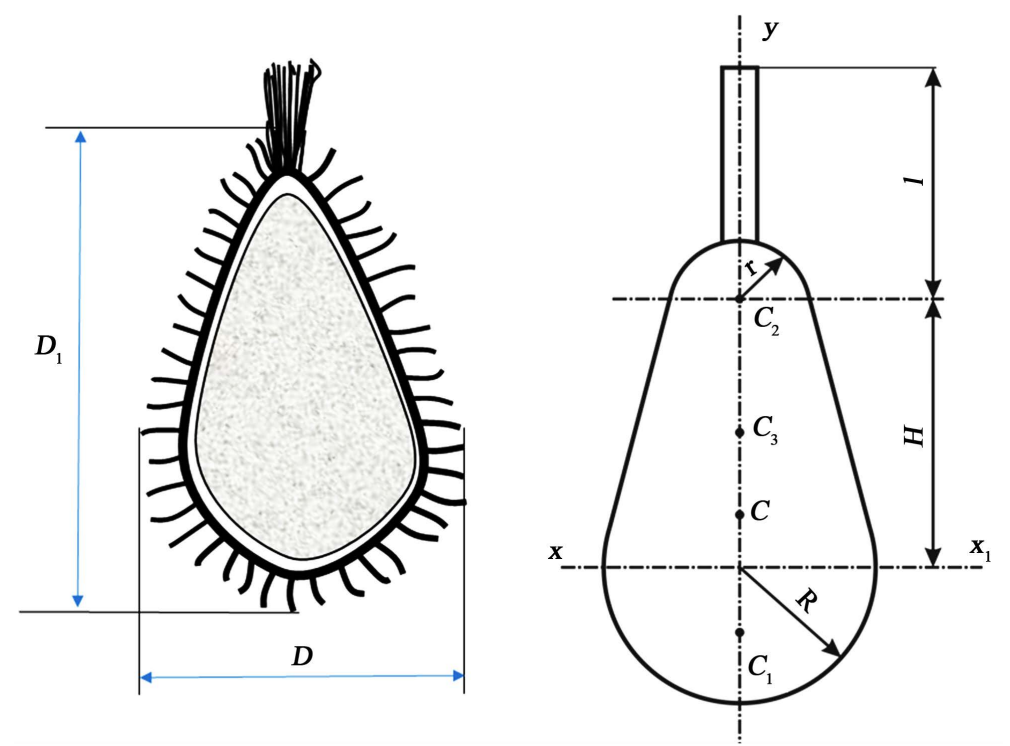

Figure 1. The scheme of ginned and accounted seeds.

In that case,

$$
\begin{gathered}
Z_{c}=\frac{\frac{3}{4} R \cdot \frac{2}{3} \pi R^{3}+\frac{H}{3} \cdot \frac{2 R}{r+R} \cdot \frac{\pi H}{3}\left(R^{2}+r^{2}-r R\right)+\left(H+\frac{3}{8} r\right) \frac{2}{3} \pi r^{3}}{\frac{2}{3} \pi R^{3}+\frac{\pi H}{3}\left(R^{2}+r^{2}-r R\right)+\frac{2}{3} \pi r^{3}} \\
Z x_{c}=\frac{Z_{b} \cdot m_{b}+Z_{c} \cdot m_{c}}{m_{b}+m_{c}}
\end{gathered}
$$

In the same way we determine the mass centre of seed that ahs "xalaza" fiber.

As it is given from the $3^{\text {rd }}$ formula, $Z x_{c}>Z n_{c}$ here the more amount of $Z_{b} \cdot m_{b}$ the bigger amount of $Z x_{c}$.

For example, for average cotton fibers $l=31-33 \mathrm{~mm}$ is accepted, then by $H$ is determined and $Z_{b}=16.5+1.3 R$.

Now let's determine a hole diameter that supplies its turning for fiber seeds in a free condition. For summing the proportion task in picture1 and taking into consideration of divergence angle of symmetry axis $1.10 D$ we determine the hole diameter [8].

We consider seed pappus dividing enough properly, in this case, the fiber screen shouldn't fit to determined diameter. Here it is just enough moving the seed cone towards fibre [9]. That means, these accepted limitations are sufficient for measure system. So, with the help of the $3^{\text {rd }}$ formula the seed mass is determined $Z x_{c}$ (Figure 2).

For example, if seed pappus mass is $0.14 \mathrm{~g}$, pappus mass is $0.2 \mathrm{~g}$, seed radius (R) is $3 \mathrm{~mm}$, then the amount of $m_{6}$ makes $m_{6}=0.0032 \mathrm{~g}$. This seed pappus mass consists $5 \%$. In this way, cotton seeds might be controlled according to the amount of fiber, here its number is less than $5 \%$ means the fiber can't change its direction towards the hole, when it is more than 5\% seeds act like pappus towards the hole, they pass over them freely. According to the comparative 


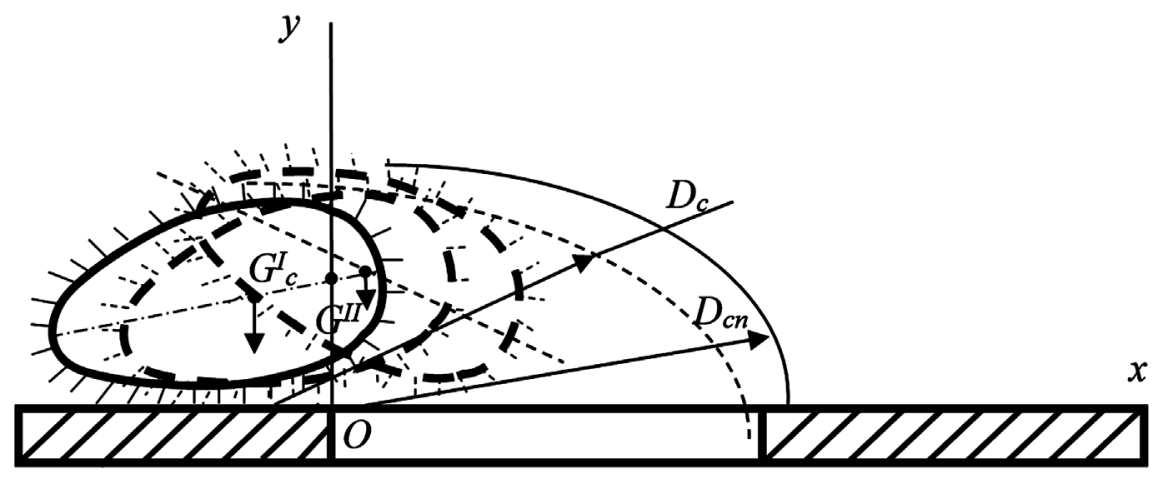

Figure 2. The collapsing scheme of seed in the net hole.

method researches' experienced results seed and pappus are separated in holes that becomes more in every $0.5 \mathrm{~mm}$ step [10].

\section{Conclusion}

Moreover, as a result of repeating the experiment, many times the same fibrous seeds weighing more than $0.0040 \mathrm{~g}$ move further than seeds with a smaller mass without getting into the hole. The increase in fiber weight by $0.0060 \mathrm{~g}$ led to the introduction of seeds into the holes, that is, to the separation of seeds according to the degree of fibrous mass. Thus, it is possible to choose the size of the holes in the mesh, which facilitates the sorting of cotton seeds by weight.

\section{Conflicts of Interest}

The authors declare no conflicts of interest regarding the publication of this paper.

\section{References}

[1] About measures on cardinal perfection of a control system of a cotton industry. Decree of the President of the Republic of Uzbekistan of 28 November 2017 No. PP-3408. Press Service of the President of the Republic of Uzbekistan. prezident.uz

[2] On measures for the accelerated development of the textile and apparel-knitting industry. Decree of the President of the Republic of Uzbekistan of December 14, 2017 No. UP-5285. Press Service of the President of the Republic of Uzbekistan. prezident.uz

[3] Burnashev, R.Z., Muradov, R. and Sarimsakov, O.Sh. (2001) Dynamic Task of Interaction of Raw Cotton with Working Bodies of Processing Machines. Journal of Problems of Mechanics, No. 34, 55.

[4] Alimova, X., Burnashev, R.Z., Sarimsakov, O.Sh., Rakhimov, 0. and Bulanov, A. (1999) Textile, Light and Polygraphic Promulgence in Market Conditions. Journal of Economic Herald of Uzbekistan, No. 1/2, 58.

[5] Akhmedkhodzhaev, H.T. (1995) Development of the Fundamentals of the Theory and Technology of Processing of Raw Cotton after Ginification. Ph.D. Dissertation, KGTU, Kostroma, 350 p.

[6] Obidov, A.A. (2007) Improvement of Technology of Cleaning and Sorting Processed Cotton Seeds. Ph.D. Dissertation, Tashkent Institute of Textile and Light 
Industry (TITLI), Tashkent.

[7] Obidov, A. (2007) Improvement of Technology of Cleaning and Sorting Processed Cotton Seeds. Ph.D. Dissertation, Tashkent Institute of Textile and Light Industry (TITLI), Tashkent, $120 \mathrm{p}$.

[8] Mardonov, B., Goyibnazarov, E. and Obidov, A. (2015) Theoretical Study of the Catcher Device Long Fiber Composition of Lint. Journal of Fergana Politechnical Institute, №2, 30-32.

[9] Abdukarimovich, M.O., Ibragimovich, A.K. and Sharipjanovich, S.O. (2018) Designing a New Design of a Loading Cylinder for Pneumomechanical Spinning Machines. Engineering, 10, 345-356. https://doi.org/10.4236/eng.2018.106025

[10] Abbazov, I., Sarimsakov, O., Khodjiev, M. and Mardonov, B. (2018) Effective Cleaning of Cotton Waste Produced at Cotton Cleaning Factories. American Journal ASCIT Communications, 5, 22-28. 